\title{
Application of Chiral Lanthanide-induced Shift Reagents to Optically Active Cations: the Use of Tris[3-(trifluoromethylhydroxymethylene)-(+)-camphorato]europium(III) to Determine the Enantiomeric Purity of Tris(phenanthroline)ruthenium(II) Dichloride
}

\author{
Jacqueline K. Barton* and James S. Nowick \\ Department of Chemistry, Columbia University, New York, NY 10027, U.S.A.
}

In non-polar solvents, chiral europium complexes provide attractive n.m.r. shift reagents to resolve spectra of optically active cations, and, in particular, for tris(phenanthroline)ruthenium dichloride, $1 \mathrm{H}$ n.m.r. shift differences of up to 0.7 p.p.m. between isomers easily permit the determination of absolute enantiomeric purity.

There has been considerable interest in the determination of enantiomeric purity by n.m.r. spectroscopy using chiral shift reagents. ${ }^{1-4}$ Although lanthanide-induced shift reagents were first used to study cations in 1973,5 chiral lanthanide-induced shift reagents have been used only with neutral species. We report the application of chiral lanthanide-induced shift reagents to optically active cations. For the following study we employed tris(phenanthroline)ruthenium(II) complexes, $\left[\mathrm{Ru}(\mathrm{phen})_{3}\right]^{2+}$, which we are currently using as chiral probes for DNA. 6

Tris(phenanthroline)ruthenium(II) dichloride was prepared as described by Lin et al. ${ }^{7}$ and partially resolved by recrystalli- 
Table 1. The effect of $\mathrm{Eu}(\mathrm{tfc})_{3}$ upon the ${ }^{1} \mathrm{H}$ n.m.r. spectrum of $\left[\mathrm{Ru}(\text { phen })_{3}\right] \mathrm{Cl}_{2} \cdot x \mathrm{H}_{2} \mathrm{O}$ in $\mathrm{CD}_{2} \mathrm{Cl}_{2}$.

\begin{tabular}{|c|c|}
\hline Proton & $\delta$, p.p.m \\
\hline $\mathrm{H}_{\mathrm{a}}$ & 8.582 \\
\hline $\mathrm{H}_{\mathrm{b}}$ & 7.815 \\
\hline $\mathrm{H}_{c}$ & 8.255 \\
\hline $\mathrm{H}_{\mathrm{d}}$ & 8.215 \\
\hline
\end{tabular}

\begin{tabular}{|c|c|c|c|c|}
\hline \multicolumn{5}{|c|}{ With $\mathrm{Eu}(\mathrm{tfc})_{3}$} \\
\hline \multicolumn{2}{|c|}{$\delta$, p.p.m. } & \multicolumn{2}{|c|}{$\Delta \delta$, p.p.m. } & \multirow[t]{2}{*}{$\Delta \Delta \delta$, p.p.m. } \\
\hline$\Delta$ & $\Lambda$ & $\Delta$ & $\Lambda$ & \\
\hline 15.833 & 16.565 & 7.251 & 7.983 & 0.732 \\
\hline \multicolumn{2}{|c|}{$16.240^{\mathrm{a}}$} & \multicolumn{2}{|c|}{$8.425^{a}$} & $\leqslant 0.08^{\mathrm{a}}$ \\
\hline 12.609 & 12.794 & 4.354 & 4.539 & 0.185 \\
\hline 11.573 & 11.798 & 3.358 & 3.583 & 0.225 \\
\hline
\end{tabular}

a The $\Delta$ - and $\Lambda-H_{b}$ quadruplets are overlapping. Values of $\delta$ and $\Delta \delta$ are given for the centre of the $H_{b}$ cluster of peaks. Differentiation between $\mathrm{H}_{\mathrm{b}}$ protons has been evident in some experiments.

zation with antimony $\mathrm{D}$-tartrate anion; 8 treatment of the tartrate with perchloric acid, sodium perchlorate, or sodium chloride yielded optically enriched perchlorate, [Ru(phen $\left.)_{3}\right]\left(\mathrm{ClO}_{4}\right)_{2} \cdot x \mathrm{H}_{2} \mathrm{O}$, or chloride, $\left[\mathrm{Ru}(\text { phen })_{3}\right] \mathrm{Cl}_{2} \cdot x \mathrm{H}_{2} \mathrm{O}$. We first attempted to observe chiral shifts of the perchlorate and chloride in $\left(\mathrm{CD}_{3}\right)_{2} \mathrm{SO}$, and of the perchlorate in $\mathrm{CD}_{2} \mathrm{Cl}_{2}$, in the presence of tris-[3-(trifluoromethylhydroxymethylene)$(+)$-camphorato]europium(III), Eu(tfc $)_{3}$. In each case, only small changes in chemical shift $(<0.15$ p.p.m. $)$ were seen, and no differentiation between enantiomers was observed.

These results are not surprising in view of the general model for lanthanide-induced shifts of cations: the anion is coordinated by the lanthanide shift reagent and the cation forms an outer-sphere complex (ion pair) with the co-ordinated anion. ${ }^{5}$ We find that the nature of the anion as well as the nature of the solvent is critical to the degree of induced shift observed. Small, highly charged anions favour co-ordination and allow the cation to approach the shift reagent more closely, yielding greater induced shifts. The use of a small anion may also enhance steric interactions between the cation and shift reagent. In addition the concentration of the ion pair-shift reagent complex is maximized in non-polar or slightly polar solvents. More polar solvents containing an atom which can co-ordinate to the shift reagent, thus competing with the anion, or which would independently solvate the ions and shift reagent, yield very small lanthanideinduced shifts. (Non-polar solvents, however, limit the solubility of ionic substrate, thus requiring a large number of pulses for a good signal-to-noise ratio.)

With these considerations in mind, we next examined the smaller chloride complex in $\mathrm{CD}_{2} \mathrm{Cl}_{2}$. From the ${ }^{1} \mathrm{H}$ n.m.r. spectrum of $\left[\mathrm{Ru}(\text { phen })_{3}\right] \mathrm{Cl}_{2} \cdot x \mathrm{H}_{2} \mathrm{O}\left(0.55 \mathrm{ml} ; 1.9 \times 10^{-3} \mathrm{M}\right)$ containing Eu(tfc) ${ }_{3}\left(2.7 \times 10^{-2} \mathrm{M}\right)$ in $\mathrm{CD}_{2} \mathrm{Cl}_{2}$, we were able to distinguish between the two enantiomers and determine the enantiomeric purity of the sample. $\dagger$ The resulting spectrum at $200 \mathrm{MHz}$ is shown in Figure 1(a) and is compared to that of the same solution in the absence of Eu(tfc $)_{3}$ in Figure 1(b).

Observed chemical shifts $(\delta)$, downfield shifts induced by the lanthanide reagent $(\Delta \delta)$, and the magnitudes of the difference in chemical shifts of analogous protons of the two enantiomers upon addition of shift reagent $(\Delta \Delta \delta)$, are summarized in Table 1 . As is shown in Table 1 , very large lanthanide-induced shifts $(\Delta \delta)$ were observed, and substantial

$\dagger$ Solutions of $\left[\mathrm{Ru}(\text { phen })_{3} \mathrm{Cl}_{2} \cdot x \mathrm{H}_{2} \mathrm{O}\right.$ were prepared by stirring an excess of the compound in $\mathrm{CD}_{2} \mathrm{Cl}_{2}$ and filtering. Eu(tfc) $3(13.2 \mathrm{mg})$ was then added and the resulting solution filtered through glass wool. Ruthenium concentrations were determined spectrophotometrically by dilution. Spectra were taken using a Varian XL-200 n.m.r. spectrometer with $\mathrm{SiMe}_{4}$ as internal standard. Assignments of peaks were made in accordance with the literature (E. C. Constable and J. Lewis, Inorg. Chim. Acta, 1983, 70, 251) on the basis of peak position and coupling constants in $\mathrm{CD}_{3} \mathrm{COCD}_{3}$.

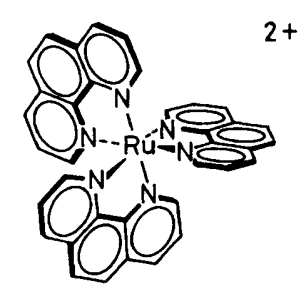

$\Lambda$
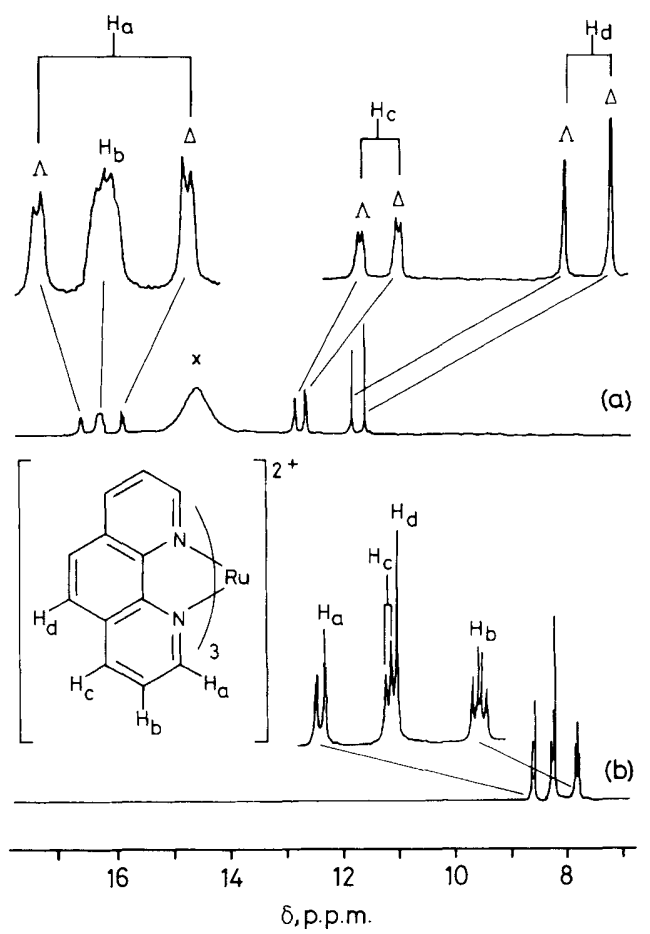

Figure 1. The 'H n.m.r. spectrum of $\Delta$-enriched [Ru(phen) ${ }_{3}$ $\left.\mathrm{Cl}_{2}\right] \cdot x \mathrm{H}_{2} \mathrm{O}$ in the presence (a) and absence (b) of Eu(tfc) ${ }_{3}$. Note the large difference in chemical shift between $H_{a 1}, H_{c}$, and $H_{a}$ of the $\Delta$ and $\Lambda$-enantiomers in the presence of Eu(tfc $)_{3}$. The broad peak. denoted $x$ in spectrum (a), is associated with the shift reagent.

differences between analogous $\mathrm{H}_{\mathrm{a}}, \mathrm{H}_{\mathrm{b}}$, and $\mathrm{H}_{\mathrm{c}}$ protons of the two enantiomers were found. It is also noteworthy that despite the high concentration of shift reagent, excessive line broadening is not evident $\left[\Delta v\left(\mathrm{H}_{\mathrm{d}}\right)=3\right.$ and $2 \mathrm{~Hz}$ in the presence and absence of Eu(tfc $)_{3}$ respectively]. Experiments with lower ratios of shift reagent to substrate $(1: 2)$ yielded smaller induced shifts $(0.2-0.5$ p.p.m.) and enantiomeric 
shift differences $(0.02-0.07$ p.p.m. $)$ with less line broadening.

The larger $\Delta \delta$ of $H_{a}$ and $H_{b}$ and smaller $\Delta \delta$ of $H_{c}$ and $H_{a}$ are consistent with an ion-pairing model for the lanthanideinduced shifts. The $\mathrm{Ru}$ (phen $)_{3}{ }^{2+}$ and $\mathrm{Eu}(\mathrm{tfc})_{3}$ species may sit on the chloride anion with the $C_{3}$ axes intersecting this anion, thus placing $\mathrm{H}_{a}$ and $\mathrm{H}_{\mathrm{b}}$ in region of greater induced shifting. The fact that $H_{a}$ and $H_{b}$ have similar $\Delta \delta$ values but very different $\Delta \Delta \delta$ suggests that there are significant conformational differences between the diastereisomeric $\Delta$-Ru(phen $)_{3}{ }^{2+}-\mathrm{Cl}--\mathrm{Eu}(\mathrm{tfc})_{3}$ and $\Lambda$-Ru(phen $)_{3}{ }^{2+}-\mathrm{Cl}--\mathrm{Eu}(\mathrm{tfc})_{3}$ complexes. It is interesting that specific donor-acceptor interactions between functional groups on the shift reagent and chiral complex are not necessary to obtain these distinct diastereoisomeric complexes. $\ddagger$

Comparison of the areas of the well resolved $\mathrm{H}_{\mathrm{d}}$ protons of the two enantiomers permitted calculation of the enantiomeric purity of the sample: the value obtained by this method supported that determined by polarimetry. ${ }^{9}$

In summary, by n.m.r. spectroscopy with chiral shift reagents we have observed differences in chemical shift between enantiomers of a cationic species, $\mathrm{Ru}(\mathrm{phen})_{3^{2+}}$, and have used this technique to determine enantiomeric purity. This direct method of determination of enantiomeric purity is more desirable than polarimetry since polarimetry requires an optically pure reference sample yet fails to guarantee that the reference sample is optically pure. We believe this work to be

\#Differential chiral induced shifts have also been obtained with $\left[\left(4,7-\mathrm{Ph}_{2} \text { phen }\right)_{3} \mathrm{Ru}\right] \mathrm{Cl}_{2}$ and Eu(tfc) $)_{3}$. With a diamagnetic chiral solvating agent, it is unlikely that such dramatic shift differences would be observed between optically active cations, even with high diastereoisomeric discrimination. the first to report the application of chiral shift reagents to cations and expect that this technique may be generally useful.

This work was supported by a grant from the National Institutes of Health. J. K. B. is a Research Fellow of the Alfred P. Sloan Foundation. We thank Jonathan M. Goldberg and Elias Lolis for providing samples of Ru(phen) $3^{2+}$ salts.

Received, 16th August 1984; Com. 1188

\section{References}

1 G. M. Whitesides and D. W. Lewis. J. Am. Chem. Soc., 1971.93, 5914; H. L. Goering, J. N. Eikenberry and G. S. Koermer, ibid, 1971, 93. 5913; M. D. McCreary, D. W. Lewis. D. L. Wernick, and G. M. Whitesides, ibid., 1974,96. 1038.

2 S. Yamaguchi, Asymm. Synth., 1983, 1, 125: R. R. Fraser, ibid., 1983, 1, 173; G. R. Sullivan, Top. Stereochem., 1978. 10, 287.

3 S. Yamaguchi and H. S. Mosher, J. Org. Chem., 1973, 38. 1870; S. Yamaguchi, F. Yasuhara and K. Kabuto, Tetrahedron, 1976. 32. 1363; W. H. Pirkle and K. A. Simmons, J. Org. Chem., 1981, 46. 3239; (d) G. R. Sullivan. J. A. Dale, and H. S. Mosher, ibid.. 1973. 38. 2143; G. R. Stephenson. Aust. J. Chem. 1982, 35. 1939.

4 G. R. Weisman, Asymm. Synth., 1983, 1, 153; W. H. Pirkle and D. J. Hoover, Top. Stereochem., 1982, 13, 263.

5 R. E. Graves and P. I. Rose, J. Chem. Soc., Chem. Commun., 1973,630 .

6 J. K. Barton, J. J. Dannenberg, and A. L. Raphael. J. Am. Chem. Soc., 1982, 104, 4967; J. K. Barton, A. T. Danishefsky, and J. M Goldberg, ibid., 1984, 106, 2172; J. K. Barton and A. L. Raphael. ibid., 1984, 106, 2466; J. K. Barton, L. A. Basile. A. Danishefsky. and A. Alexandrescu, Proc. Natl. Acad. Sci. USA, 1984, 81. 1961

7 C-T. Lin, W. Bottcher, M. Chou, C. Creutz, and N. Sutin, J. Am. Chem. Soc., 1976, 98, 6536.

8 R. D. Gillard and R. E. E. Hill, J. Chem. Soc., Dalton Trans., 1974,1217

9 S. F. Mason and B. J. Peart, J. Chem. Soc., Dalton Trans., 1973. 949. 